\title{
G2-checkpoint abrogation in irradiated lymphocytes: A new cytogenetic approach to assess individual radiosensitivity and predisposition to cancer
}

\author{
GEORGIA I. TERZOUDI ${ }^{1}$, VASILIKI I. HATZI ${ }^{1}$, KATARZYNA BARSZCZEWSKA ${ }^{1}$, KALLIOPI N. MANOLA ${ }^{1}$, \\ CHRYSSA STAVROPOULOU ${ }^{1}$, PHILIP ANGELAKIS ${ }^{2}$ and GABRIEL E. PANTELIAS ${ }^{1}$ \\ ${ }^{1}$ Radiobiology and Cytogenetics, National Center for Scientific Research 'Demokritos'; \\ ${ }^{2}$ Radiotherapy Department, Diagnostic and Therapeutic Center of Athens 'Hygeia' S.A., Athens, Greece
}

Received July 29, 2009; Accepted August 13, 2009

DOI: 10.3892/ijo_00000439

\begin{abstract}
Increased yield of chromatid breaks, following in vitro G2-phase lymphocyte irradiation, can be a marker of individual radiosensitivity and cancer predisposing genes whose role is to respond to DNA damage. Mutations or polymorphisms of genes encoding DNA repair pathways may underlie the increased chromosomal radiosensitivity. However, genes that facilitate DNA damage recognition, using signal transduction pathways to activate cell cycle arrest and preserve genomic integrity, are perhaps the most important determinant. Based on the latter hypothesis, an individual radiosensitivity parameter (IRP) is introduced, which expresses, at individual level, the G2-checkpoint potential to facilitate DNA damage recognition and repair of radiation-induced chromosomal damage during G2 to M-phase transition. Based on this parameter a new methodology for assessment of individual radiosensitivity is proposed, which involves G2checkpoint abrogation by caffeine to obtain the IRP values. To evaluate the proposed methodology, blood samples from 52 healthy donors were taken for inter-individual radiosensitivity analysis using both the conventional G2 chromosomal radiosensitivity assay as well as the new approach using caffeineinduced G2-checkpoint abrogation. The two assays were compared in experiments using samples from 5 hypersensitive patients, 3 AT-homozygotes, 3 AT-heterozygotes, and the GM15786, GM03188A, GM09899, HCC1937 and MCF-7 cell lines. Using the $\mathrm{G} 2$ chromosomal radiosensitivity assay, donors are predicted as $\mathrm{G} 2$ radiosensitive or normal, while according to the new approach, individuals can be classified as highly radiosensitive, radiosensitive, normal, radioresistant and highly radioresistant. Overall, the new approach provides better individual radiosensitivity discrimination and intra-
\end{abstract}

Correspondence to: Drs Gabriel E. Pantelias or Georgia I. Terzoudi, Radiobiology and Cytogenetics, IR-RP, NCSR 'Demokritos', 15310 Agia Paraskevi, Athens, Greece

E-mail: gabriel@ipta.demokritos.gr; gterzoudi@rrp.demokritos.gr

Key words: individual radiosensitivity, predisposition to cancer, G2-assay, G2-checkpoint abrogation, caffeine, individual radiosensitivity parameter (IRP), chromatid breaks experimental reproducibility. Therefore, the proposed methodology using IRP values may provide a clinically applicable predictive assay for individual radiosensitivity and predisposition to cancer.

\section{Introduction}

Identification of individuals in the normal population with increased inherent radiosensitivity is of relevance for their protection from the adverse effects of radiation and other genotoxic agents, with applicability in occupational health and safety. Also, in radiation oncology, since it is known that the maximum therapeutic radiation dose is limited by the occurrence of normal tissue adverse effects (1), the individualization of radiation therapy protocols can be uniquely facilitated by the prediction of individual radiosensitivity (2-7). Furthermore, as it is well established that cellular radiosensitivity is linked to cancer predisposition $(8,9)$, population screening for hypersensitivity to radiation is of great importance (reviewed in ref. 10).

In recent years, evidence has been obtained to support the hypothesis that possession of variants in genes, which play a role in radiation response, is predictive for individual radiosensitivity and the development of adverse effects after radiotherapy $(7,11,12)$. Yet, in vitro irradiation of peripheral blood lymphocytes using techniques measuring DNA or chromosome damage, and in particular G2 chromosomal radiosensitivity (G2 assay), is also extensively applied for individual radiosensitivity assessment (13-17). Specifically, the cell cycle based G2 assay involves the in vitro irradiation of peripheral blood lymphocytes in G2 phase to induce DNA damage, which is processed during G2 to M-phase transition so that the residual lesions can be visualized and quantified at metaphase as chromatid breaks. Variation in the yield of chromatid breaks between individuals has been correlated to variation in radiosensitivity and predisposition to cancer $(13,18-20)$. Current protocols for the G2 assay require stringent technical conditions (16) to generate reproducible and meaningful results, and variability in yields of induced chromatid breaks in different samples from the same individual is a recognized problem. The original method developed by Sanford et al (13) has been refined by Scott et al (20) in order to minimize problems associated with 
reproducibility and obtain better discrimination. At present, however, comparisons of the results between different laboratories are difficult since modifications in the protocols used result in variations in the yield of chromatid breaks and reproducibility $(16,21)$. Furthermore, an important issue associated with the sensitivity of G2 assay is that, although the mean radiation-induced yield of chromatid breaks in certain groups, such as cancer patients, is significantly higher than in normal individuals, considerable overlap is found in the yield of G2 chromatid breaks $(19,22-27)$. Therefore, a G2 radiosensitive cut-off value has to be calculated from the control population in order to assess individual radiosensitivity. In some of the studies, the 90th percentile of the distribution of results from a normal population is taken as cut-off point. This cut-off point, as introduced first by Scott et al (19), is obviously very helpful, even though it is arbitrary and very dependent on the extent of the healthy control group (17).

In the present study, a new approach is proposed for individual radiosensitivity assessment aiming to provide better discrimination of individual radiosensitivity and intraexperimental reproducibility, as well as to minimize the required stringent technical conditions of the current protocol used for the G2 assay. The methodology is based on our previous work related to the mechanisms underlying conversion of DNA damage into chromatid breaks, which is linked to cell-cycle and feedback control mechanisms and, particularly, to the cdk1/cyclin-B (MPF) complex activity that regulates G2 to M-phase transition (22,28-30). It exploits also our observation that checkpoint abrogation in G2 phase by means of caffeine compromises repair of radiationinduced chromosomal damage, which can be increased to the levels obtained in the case of highly radiosensitive ataxia telangiectasia (AT) patients $(31,32)$. According to the new approach, two yields of chromatid breaks are obtained for each individual in response to radiation-induced DNA damage during G2 to M-phase transition of cultured peripheral blood lymphocytes. The first represents residual chromosomal damage under the effect of the G2 checkpoint, and the second under G2-checkpoint abrogation by means of caffeine. We propose that the difference between these two G2 values can be employed as an individual radiosensitivity parameter (IRP) to assess intrinsic radiosensitivity and predisposition to cancer since it reflects differences among individuals in specific mutations or polymorphisms in genes that control: a) DNA repair capacity, b) cdk1/cyclin B activity and c) G2-checkpoint activation after irradiation during the G2 to M-phase transition. Essentially, the obtained IRP value expresses, at individual level, the G2-checkpoint potential to facilitate DNA damage recognition and repair of radiation-induced chromosomal damage during G2 to M-phase transition. Consequently, the lower the IRP value, the higher the radiosensitivity of the individual and, as the IRP value approaches to zero, the predictive individual radiosensitivity will be close to that of AT patients.

\section{Materials and methods}

Blood samples and cell lines. After obtaining consent, heparinized blood samples $(5 \mathrm{ml})$ were taken from 52 healthy control subjects for inter-individual variation analysis of radiosensitivity using both the conventional G2 assay, as described in previous work (22), and the new approach that, in addition, takes into consideration for each individual the yield of chromatid breaks obtained when G2 checkpoint is inactivated after irradiation, by means of caffeine. Blood samples were also taken from five cancer patients who experienced adverse radiation effects from their radiation therapy treatment, three clinically characterized AT homozygotes and three obligate AT heterozygotes. Peripheral blood lymphocytes were cultured adding $0.5 \mathrm{ml}$ of whole blood to $5 \mathrm{ml}$ of McCoy's 5A medium supplemented with 10\% FBS, $1 \%$ phytohaemagglutinin (PHA), $1 \%$ glutamine and antibiotics (penicillin: $100 \mathrm{U} / \mathrm{ml}$; streptomycin: $100 \mu \mathrm{g} / \mathrm{ml}$ ). Cultures were incubated for $72 \mathrm{~h}$ before their use for radiosensitivity estimation experiments. In addition, three EBV-transformed lymphoblastoid cell lines (LCL) were used: GM 15786, derived from an AT patient, GM03188A from an obligatory ATM heterozygote and GM 09899, derived from a normal individual. Cells were maintained in RPMI (Biochrom AG, Germany) supplemented with HEPES and sodium bicarbonate, $15 \%$ fetal bovine serum (FBS), $2 \mathrm{mM}$ L-glutamine and $100 \mu \mathrm{g} / \mathrm{ml}$ streptomycin and $100 \mathrm{U} / \mathrm{ml}$ penicillin. Experiments were also carried out using breast cancer cell lines, the BRCA1-defective HCC1937 cell line, homozygous for the BRCA1 5382C mutation, and the MCF-7 human breast adenocarcinoma cell line. Both HCC1937 and MCF-7 cell lines were purchased from the American Type Culture Collection (Rockville, MD, USA). HCC1937 cells were grown in RPMI-1640 medium (Biochrom AG, Germany), while MCF-7 cells were grown in Dulbecco's modified Eagle's medium (DMEM) (Biochrom AG, Germany). Culture media were supplemented with $10 \%$ fetal bovine serum (FBS), $2 \mathrm{mM}$ L-glutamine and antibiotics. All incubations took place at $37^{\circ} \mathrm{C}$ in a humidified incubator in an atmosphere of $5 \% \mathrm{CO}_{2}$ and $95 \%$ air.

Irradiation conditions and the new individual radiosensitivity assay. Irradiation was carried out in a GammaCell 220 irradiator (Atomic Energy of Canada Ltd., Ottawa, Canada) at room temperature and at a dose rate of $1 \mathrm{~Gy} / \mathrm{min}$. PHA was dissolved in water at a concentration of $0.24 \mathrm{mg} / \mathrm{ml}$. Caffeine was prepared as a $100 \mathrm{mM}$ stock solution in PBS. Proliferating cells were irradiated in vitro in G2-phase with 1 Gy and the culture was divided immediately after so that, one half was treated with caffeine $(4 \mathrm{mM})$ and incubated for $30 \mathrm{~min}$ at $37^{\circ} \mathrm{C}$ to allow division of cells irradiated at mitosis, while the other half was cultured for the same time period without the presence of caffeine. Colcemid was subsequently added to the cell cultures for $60 \mathrm{~min}$. At $90 \mathrm{~min}$ post irradiation, cells were collected by centrifugation, treated in $75 \mathrm{mM}$ $\mathrm{KCl}$ for $10 \mathrm{~min}$, fixed in methanol: glacial acetic acid (3:1 v/v) and processed for cytogenetics analysis. Standard procedures were used for chromosome preparation and staining and chromosomal damage was visualized and quantified as chromatid breaks in cells at metaphase. For each experimental point, approximately 50 cells were scored for chromatid damage based on standard criteria. Chromatid breaks and gaps were scored, the latter only when longer than a chromatid width. Light microscopy was coupled with an image analysis 


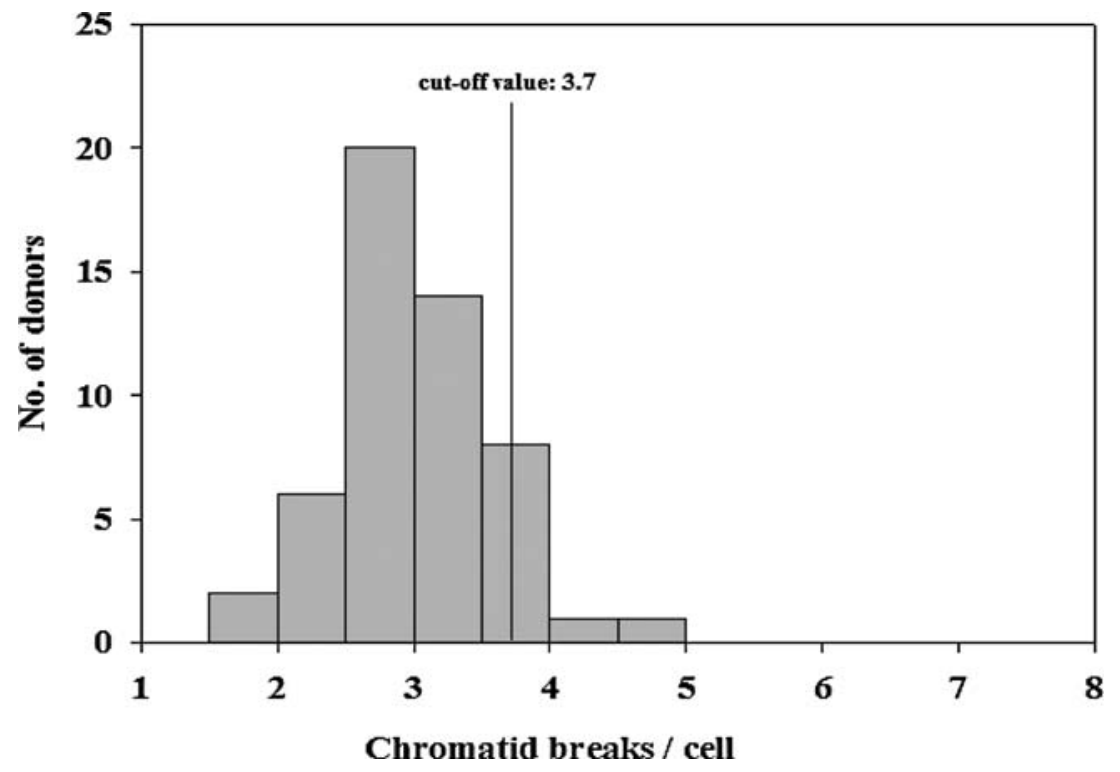

Figure 1. Inter-individual variation in chromosomal radiosensitivity obtained from 52 healthy blood donors using the conventional G2 assay. Plotted mean values are calculated from three independent experiments. The radiosensitive cut-off value, statistically set at the 90 th percentile, was found to be 3.7 chromatid breaks/cell. Consequently, $9.6 \%$ of the control population can be defined as G2 radiosensitive.

system (MetaSystems, Germany) to facilitate scoring. The spontaneous aberration yield was subtracted to obtain the radiation-induced G2 yield of chromatid breaks. Standard deviations of the mean values from three independent experiments were calculated. Following this protocol, chromosomes were analyzed at the subsequent metaphase and two distinct yields of chromatid breaks were obtained for each individual or cell line after G2-phase irradiation. One yield corresponded to that obtained when the conventional G2 assay was applied, and the other represented, for each individual, the maximum yield of chromatid breaks obtained when G2 checkpoint was inactivated by means of caffeine.

\section{Results}

Inter-individual variation in radiosensitivity obtained using the conventional G2 assay. For the conventional G2 assay, peripheral blood lymphocyte cultures were stimulated and $72 \mathrm{~h}$ thereafter cells were irradiated with $1 \mathrm{~Gy}$. Chromosome preparation and yield analysis of chromatid breaks were carried out as described in the 'Materials and methods' section. Fig. 1 shows the inter-individual variation in chromosomal radiosensitivity as measured for 52 healthy blood donors. Experiments were carried out on a single blood sample per blood donor and standard deviations of the mean values from three independent experiments were calculated. As mentioned above, the identification of radio-sensitive individuals in the conventional G2 assay involves the calculation of a radiosensitive cut-off value above which an individual can be considered to be radiosensitive. This radiosensitive cut-off value can be statistically set at the 90th percentile, i.e., the value below which $90 \%$ of the controls lie (19). Using this approach for the 52 healthy blood donors, we obtained a cut-off value of 3.7 chromatid breaks per metaphase and $9.6 \%$ of the control population was defined as $\mathrm{G} 2$ radiosensitive.
Inter-individual variation in radiosensitivity as predicted using the new approach. Peripheral blood lymphocytes were irradiated in vitro in $\mathrm{G} 2$ phase and subsequently cultured with and without caffeine, so that two distinct yields of chromatid breaks were obtained when chromosomes were analyzed at the subsequent metaphase. While Fig. 2A shows the chromatid breaks as visualized at metaphase following the conventional G2 assay, Fig. 2B shows the chromatid breaks obtained following G2-checkpoint abrogation by means of $4 \mathrm{mM}$ of caffeine. Under these experimental conditions, an increased yield of chromatid breaks similar to that obtained in AT patients can be observed. For each individual, these two yields of chromatid breaks represent residual chromosomal damage with and without G2-checkpoint activation in response to radiation-induced DNA damage. The yield obtained when G2 checkpoint is inactivated by means of caffeine is used as an internal control value and represents a maximum $\mathrm{G} 2$ radiosensitivity value for each individual. The difference between the two yields obtained is characteristic for each individual, as it reflects differences in specific mutations or polymorphisms in genes that control recognition and the processing of radiation-induced DNA damage during G2 to M-phase transition. We define the difference between these two yields of chromatid breaks as individual radiosensitivity parameter (IRP). Fig. 3 shows the inter-individual variation in IRP values obtained from the 52 healthy control blood donors. The inter-individual variation in radiosensitivity, as expressed by variation in the IRP values, is fitted by a normal distribution with a mean value (MV) of 4.7 chromatid breaks per metaphase, a standard deviation (SD) of 0.8 , and $17 \%$ coefficient of variation (CV). According to the proposed method, individuals may be defined as normal when IRP $=\mathrm{MV} \pm \mathrm{SD}$, sensitive when $\mathrm{MV}-2 \mathrm{SD} \leq \mathrm{IRP}<\mathrm{MV}-\mathrm{SD}$, highly sensitive when IRP $<M V-2 S D$, resistant when $\mathrm{MV}+\mathrm{SD}<\mathrm{IRP} \leq \mathrm{MV}+2 \mathrm{SD}$, and highly resistant when IRP $>$ $\mathrm{MV}+2 \mathrm{SD}$. According to these criteria, $77 \%$ of healthy donors 
A

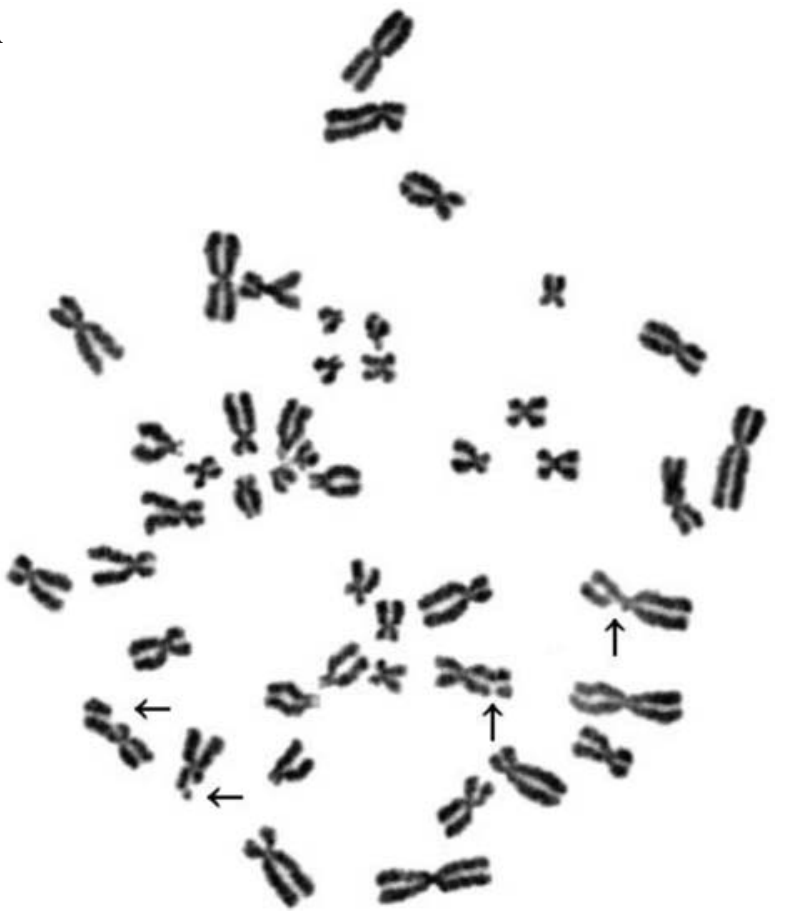

B
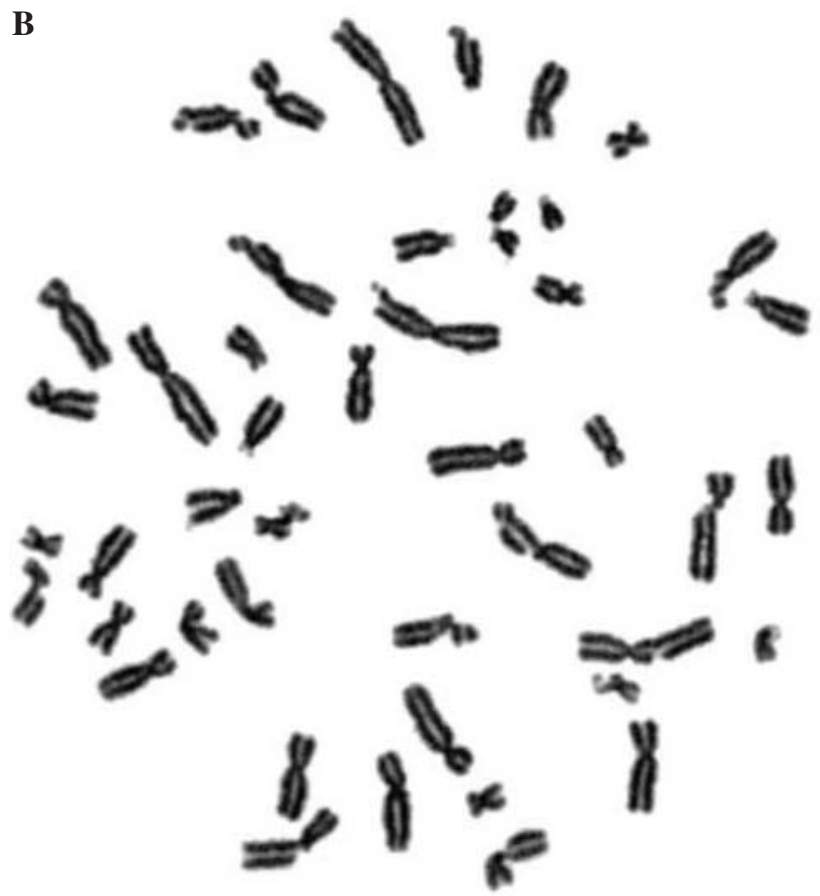

Figure 2. Chromatid breaks after 1 Gy of $\gamma$-irradiation as visualized at a metaphase peripheral blood lymphocyte from a healthy donor, (A) using the conventional G2 assay, (B) applying G2-checkpoint abrogation by means of caffeine. Notice three chromatid breaks and one chromatid gap in (A), and a dramatic increase in chromatid breaks (13 chromatid breaks can be visualized) in (B).

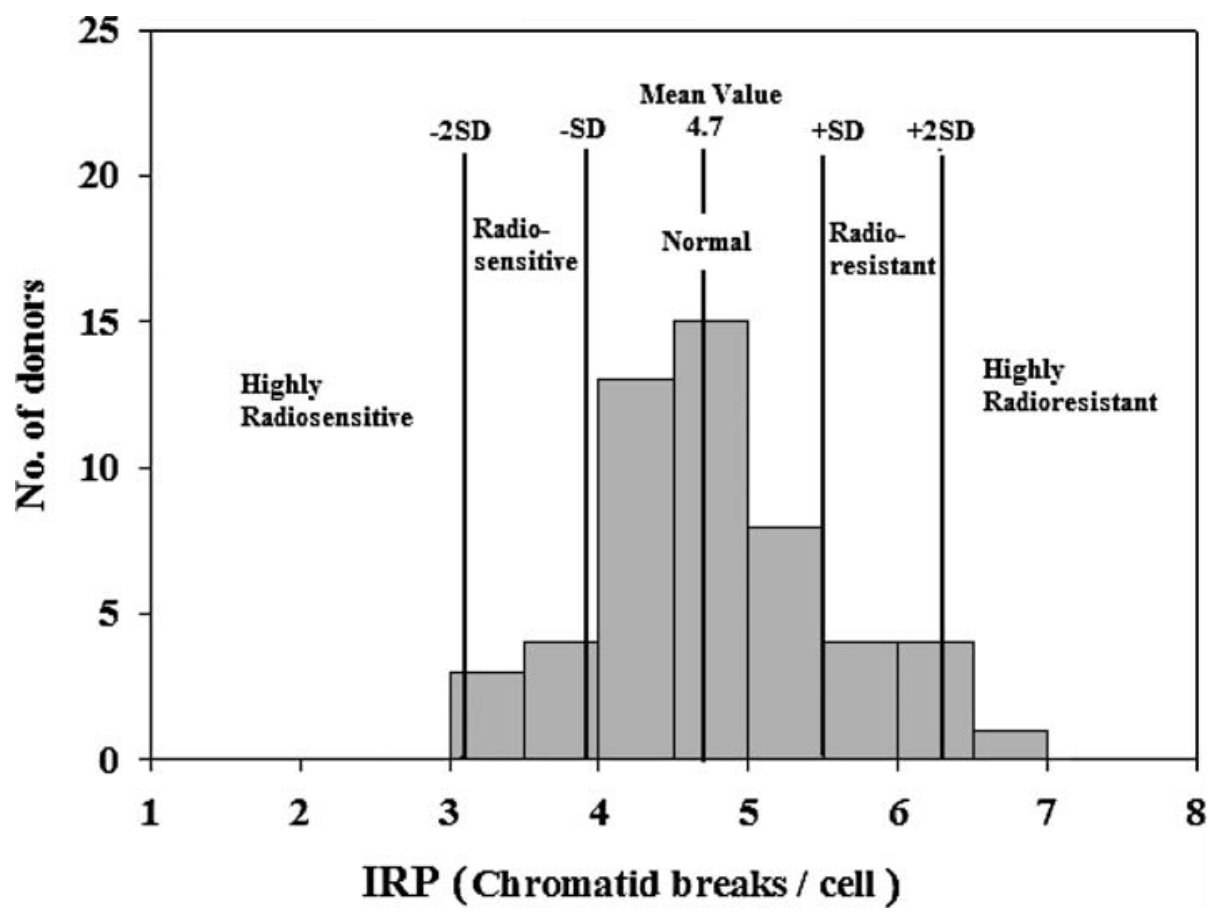

Figure 3. Inter-individual variation in chromosomal radiosensitivity for 52 healthy blood donors based on the IRP values obtained using the new approach with G2-checkpoint abrogation by means of caffeine. A mean IRP value (MV) of 4.7 chromatid breaks per metaphase was found, with a standard deviation (SD) of 0.8. A theoretical classification based on the MV and SD was applied, so that blood donors were classified as normal for IRP values in the range of $\mathrm{MV} \pm \mathrm{SD}$, as sensitive when $\mathrm{MV}-2 \mathrm{SD} \leq \mathrm{IRP}<\mathrm{MV}-\mathrm{SD}$, as highly sensitive when $\mathrm{IRP}<\mathrm{MV}-2 \mathrm{SD}$, as resistant when $\mathrm{MV}+\mathrm{SD}<\mathrm{IRP} \leq \mathrm{MV}+2 \mathrm{SD}$, and as highly resistant when IRP $>M V+2 S D$.

were found to have a normal radiosensitivity response, $9 \%$ were radiosensitive, $12 \%$ were radioresistant, while $2 \%$ were highly radioresistant.
Evaluation of the proposed $G 2$ chromosomal radiosensitivity assay. Three sets of experiments were carried out to investigate whether better discrimination in individual radiosensitivity 
Table I. G2 chromosomal radiosensitivity obtained for five cancer patients, who had experienced adverse radiation effects from their radiation therapy treatment (positive radiosensitive controls). ${ }^{\mathrm{a}}$

\begin{tabular}{|c|c|c|c|}
\hline \multirow[t]{2}{*}{ Radio-sensitive patients } & Active G2 checkpoint & $\begin{array}{c}\text { G2 checkpoint abrogated } \\
\text { by caffeine }\end{array}$ & $\begin{array}{l}\text { Individual radiosensitivity } \\
\text { parameter (IRP) }\end{array}$ \\
\hline & Chromatid breaks/cell $\pm \mathrm{SD}^{\mathrm{b}}$ & Chromatid breaks/cell $\pm \mathrm{SD}^{\mathrm{b}}$ & Chromatid breaks/cell $\pm \mathrm{SD}^{\mathrm{b}}$ \\
\hline A & $3.3 \pm 0.4$ & $6.1 \pm 0.8$ & $2.8 \pm 0.1$ \\
\hline B & $5.2 \pm 0.9$ & $8.6 \pm 0.7$ & $3.4 \pm 0.3$ \\
\hline $\mathrm{C}$ & $3.5 \pm 0.4$ & $7.2 \pm 0.9$ & $3.7 \pm 0.2$ \\
\hline D & $4.9 \pm 1.0$ & $8.1 \pm 1.0$ & $3.2 \pm 0.2$ \\
\hline $\mathrm{E}$ & $5.8 \pm 1.1$ & $9.1 \pm 0.9$ & $3.3 \pm 0.2$ \\
\hline
\end{tabular}

${ }^{a}$ Conventional G2 assay was applied (active G2-checkpoint values) as well as the new approach with G2-checkpoint abrogation by caffeine, in order to obtain the IRP values. Patients A and C are classified as normal by means of the G2 assay based on Fig. 1, whereas using the IRP values patients $\mathrm{A}$ and $\mathrm{C}$ are classified as radiosensitive according to Fig. 3 . ${ }^{\mathrm{b}}$ Mean values $\pm \mathrm{SD}$ are calculated from three independent experiments.

and intra-experimental reproducibility can be obtained by means of the proposed new approach as compared to the conventional G2 assay. In the first set of experiments, heparinized blood samples were obtained from five cancer patients who experienced adverse radiation effects from their radiation therapy treatment (radiosensitive positive controls). Individual radiosensitivity was estimated using both the conventional G2 assay and the new approach. The G2 yields with and without G2-checkpoint activation in response to radiation-induced DNA damage during G2 to M-phase transition, as well as the IRP values obtained are shown in Table I. According to the conventional G2 assay and the calculated cut-off value of 3.7 chromatid breaks per metaphase cell, only three out of the five positive controls (radiosensitive patients) who had G2 yields of 4.9, 5.2 and 5.8 chromatid breaks per cell (Table I) should belong to the radiosensitivity range (Fig. 1). However, using the new approach for the assessment of individual radiosensitivity and the IRP values shown in Table I, all five positive controls are predicted to be radiosensitive (Fig. 3).

In the second set of experiments, heparinized blood samples from three clinically characterized AT homozygotes and three obligate AT heterozygotes were used to study individual radiosensitivity by means of the conventional G2 assay as well as the proposed methodology using IRP values. The results are shown in Table II. Even though the AT homozygotes are predicted to be radiosensitive by means of the $\mathrm{G} 2$ assay, according to the proposed methodology using the IRP values they are characterized as highly radiosensitive (Fig. 3). Furthermore, when the obligate AT heterozygotes are tested for intrinsic radiosensitivity, they are predicted to be in the upper normal radiosensitivity range by means of the conventional G2 assay, whereas using the IRP values and the new methodology the AT heterozygotes (Table II) are predicted to be in the radiosensitive range (in the range of 3.1-3.9 chromatid breaks/cell).

The purpose of the third set of experiments was to test the reproducibility of the two methodologies with respect to inter- and intra-individual variation. MCF-7 cells, HCC1937 cells and three lymphoblastoid cell lines, GM15786, GM03188 and GM09899, derived from an AT patient, an obligatory AT heterozygote, and a normal individual, respectively, were used in this set of experiments. The G2 assay and the new approach using IRP values were applied to those five cell lines to measure inter- and intra-individual variation in radiosensitivity. For this purpose, two samples were taken from each cell line at three different time points. Since the MCF-7 and HCC1937 cells have a modal number of 81 and 100 chromosomes, respectively, the chromatid breaks per cell were normalized to 46 chromosomes. The results are presented in Table III, where coefficients of variation are compared between the conventional G2 assay and the new proposed methodology with IRP values, to evaluate intraexperimental reproducibility.

\section{Discussion}

Experimental results from patients with chromosomal instability syndromes and genetic susceptibility to carcinogenesis show similar cellular features as well as increased radiation sensitivity and have provided a link between chromosomal radiosensitivity and cancer predisposition. In fact, when the G2 chromosomal radiosensitivity assay (G2 assay) was applied to cancer-prone syndromes such as AT patients, Nijmegen breakage syndrome (NBS), and AT-like disorder (ATLD), and to many cancer patients as well, as reviewed in ref. 10, an increased chromosomal radiosensitivity was obtained $(13,19,22,32,33)$. Early studies and data obtained using the G2 assay on lymphocytes and skin fibroblasts were carried out and reported by Sanford, Parshad and colleagues at the National Cancer Institute (NCI), USA (34-36). However, their results could not be reproduced in another laboratory (33) and a modified protocol that generated promising results was proposed $(9,19,37,38)$. Recently, the radiosensitivity of human lymphocytes measured using a G0 or G2 assay has been linked with an individual's risk of developing normal tissue complications following radiotherapy, and a theoretical classification into three categories 
Table II. G2 chromosomal radiosensitivity obtained for three AT heterozygotes and three AT homozygotes patients. ${ }^{a}$

\begin{tabular}{llll}
\hline Donors & Active G2 checkpoint & $\begin{array}{c}\text { G2 checkpoint abrogated } \\
\text { by caffeine }\end{array}$ & $\begin{array}{c}\text { Individual radiosensitivity } \\
\text { parameter (IRP) }\end{array}$ \\
\cline { 2 - 3 } & $\begin{array}{c}\text { Chromatid breaks/cell } \\
\text { Chromatid breaks/cell }\end{array}$ & Chromatid breaks/cell $^{\mathrm{b}}$ & \\
\hline
\end{tabular}

\begin{tabular}{|c|c|c|c|}
\hline \multicolumn{4}{|c|}{ ATM+/- } \\
\hline A & $3.5 \pm 0.6$ & $7.1 \pm 1.0$ & $3.6 \pm 0.3$ \\
\hline B & $3.9 \pm 0.7$ & $7.3 \pm 0.9$ & $3.4 \pm 0.2$ \\
\hline $\mathrm{C}$ & $2.9 \pm 0.5$ & $6.8 \pm 0.9$ & $3.9 \pm 0.3$ \\
\hline \multicolumn{4}{|c|}{ ATM-/- } \\
\hline $\mathrm{D}$ & $6.5 \pm 0.9$ & $7.9 \pm 1.1$ & $1.4 \pm 0.09$ \\
\hline $\mathrm{E}$ & $6.9 \pm 1.0$ & $7.8 \pm 0.9$ & $0.9 \pm 0.08$ \\
\hline $\mathrm{F}$ & $7.9 \pm 1.0$ & $8.6 \pm 1.0$ & $0.7 \pm 0.08$ \\
\hline
\end{tabular}

${ }^{a}$ Conventional G2 assay was applied (active G2-checkpoint values) as well as the new approach with G2-checkpoint abrogation by caffeine, in order to obtain the IRP values to be checked against the ranges showed in Fig. 3. Using the conventional G2 assay, only one of the $\mathrm{ATM}+$ /- patients is predicted to be radiosensitive, whereas all three ATM+/- patients are predicted as radiosensitive when IRP values are used. All three ATM-/- patients are predicted to be radiosensitive by means of the G2 assay, whereas they are classified as highly radiosensitive according to the IRP values obtained. ${ }^{b}$ Mean values \pm SD are calculated from three independent experiments.

Table III. G2 chromosomal radiosensitivity for five cell lines as analyzed by means of the conventional G2 assay and the G2checkpoint abrogation by caffeine to obtain the IRP values. ${ }^{\mathrm{a}}$

\begin{tabular}{|c|c|c|c|c|c|c|c|c|c|}
\hline \multirow[t]{2}{*}{ Cell lines } & \multicolumn{3}{|c|}{ Active $\mathrm{G} 2$ checkpoint } & \multicolumn{3}{|c|}{$\begin{array}{c}\text { G2 checkpoint abrogated } \\
\text { by caffeine }\end{array}$} & \multicolumn{3}{|c|}{$\begin{array}{l}\text { Individual radiosensitivity } \\
\text { parameter (IRP) }\end{array}$} \\
\hline & $\begin{array}{l}\text { Chromatid } \\
\text { breaks/cell }^{\mathrm{b}}\end{array}$ & SD & $\begin{array}{l}\mathrm{CV} \\
(\%)\end{array}$ & $\begin{array}{l}\text { Chromatid } \\
\text { breaks/cell }\end{array}$ & SD & $\begin{array}{l}\mathrm{CV} \\
(\%)\end{array}$ & $\begin{array}{l}\text { Chromatid } \\
\text { breaks/cell }{ }^{\mathrm{b}}\end{array}$ & SD & $\begin{array}{l}\mathrm{CV} \\
(\%)\end{array}$ \\
\hline MCF-7 & $6.3^{\mathrm{c}}$ & 0.8 & 12.7 & $10.1^{\mathrm{c}}$ & 1.1 & 11.2 & $3.8^{\mathrm{c}}$ & 0.3 & 7.9 \\
\hline HCC1937 & $3.1^{\mathrm{c}}$ & 0.7 & 22.6 & $5.1^{\mathrm{c}}$ & 0.6 & 11.0 & $2.0^{\mathrm{c}}$ & 0.1 & 5.0 \\
\hline GM03188 & 4.0 & 0.6 & 15.0 & 8.2 & 1.0 & 12.2 & 4.2 & 0.4 & 9.5 \\
\hline GM15786 & 8.9 & 1.1 & 12.4 & 9.8 & 1.1 & 11.2 & 0.9 & 0.1 & 11.1 \\
\hline GM09899 & 2.0 & 0.3 & 15.0 & 9.2 & 1.1 & 12.0 & 7.2 & 0.8 & 11.1 \\
\hline
\end{tabular}

${ }^{a}$ Better individual radiosensitive discrimination is predicted with the new approach and, moreover, the lower CV values obtained suggest better intra-experimental reproducibility when the new approach is applied. ${ }^{b}$ Mean values \pm SD are calculated from three independent experiments carried out at various time intervals. ${ }^{c}$ Mean value normalized to 46 chromosomes.

(resistant, normal and sensitive) was introduced $(6,15)$. There was, however, no inter-assay correlation between the G0 and $\mathrm{G} 2$ sensitivity demonstrating that these two sensitivities depend on different genetic factors.

Although repair mechanisms such as homologous recombination and non-homologous end joining are important responses to double-strand DNA and chromosomal damage (39-43), cell-cycle regulation is perhaps the most important determinant of radiation sensitivity in G2 phase cells (32) and therapeutic radiosensitivity could be improved through modulation of the cell cycle (44). This hypothesis is corroborated by the results shown in Fig. 2B. Indeed, the presence of caffeine increases the yield of chromatid breaks in healthy donors to the levels obtained when lymphocytes from the highly radiosensitive AT patients are irradiated. Even though caffeine is known to influence radiation induced chromosomal damage and has been used to study inter-individual variation in chromosomal aberrations (47) and detection of AT heterozygotes (48), the precise mechanism of caffeine's action is not well understood. This may be linked to the cellcycle modulation and G2-checkpoint abrogation by means of caffeine and particularly, to the activity of the cdk $1 /$ cyclin-B complex and the subsequent changes in chromatin conformation that facilitate conversion of DNA damage into chromatid breaks. As we have already reported in previous work, following exposure to ionizing radiation, chromatin conform- 
ation changes play a vital role in the formation of chromatid breaks during premature chromosome condensation induction, as well as during G2 to M-phase transition (22,28-30). Therefore, the yield of chromatid breaks obtained in the presence of caffeine can be used for each individual as an internal control value that provides maximum chromosomal damage when the G2 checkpoint is inactivated. Since fewer chromatid breaks are obtained when G2 checkpoint is not inactivated by caffeine (Fig. 2A), the difference between these two yields is defined here as the individual radiosensitivity parameter (IRP). This parameter expresses the cell potential for DNA damage recognition and repair of chromosomal damage during G2 to M-phase transition and its value depends on the effectiveness of the G2 checkpoint. Consequently, the lower the IRP value, the higher the radiosensitivity of the individual and, as the IRP value approaches to zero, the predictive individual radiosensitivity will be close to that of AT patients.

The results obtained demonstrate that the new method provides better discrimination of radiosensitivity prediction at individual level and also intra-experimental reproducibility. Using the conventional G2 assay, a cut-off value based on the 90th percentile classifies the individual radiosensitivity in two groups, normal and radiosensitive (Fig. 1), while using the new approach, individuals can be classified as highly radiosensitive, radiosensitive, normal, radioresistant or highly radioresistant (Fig. 3). As shown in Fig. 1, a percentage of $9.6 \%$ from the 52 healthy donors can be classified as radiosensitive, whereas, according to the proposed method, a more detailed classification can be obtained. Indeed, $2 \%$ are defined as highly radioresistant, $12 \%$ as radioresistant, $77 \%$ as normal, $9 \%$ as radiosensitive, and $0 \%$ as highly radiosensitive. The advantage of the proposed methodology is clearly shown when blood samples from five cancer patients, who were clinically characterized as radiosensitive, were tested for individual radiosensitivity using both methodologies. Two out of the five positive controls (with adverse reactions) had G2 values of 3.3 and 3.5 chromatid breaks per cell (Table I) and, therefore, were predicted to be in the normal radiosensitivity range. However, using the new approach for the assessment of individual radiosensitivity and the IRP values shown in Table I, all five positive controls were predicted to be radiosensitive. In addition, when three obligate AT heterozygotes were tested for intrinsic radiosensitivity, they were predicted to be in the upper normal radiosensitivity range by means of the conventional G2 assay. However, using the new methodology, the IRP values obtained (Table II) show that all three AT heterozygotes were in the radiosensitive range. In the case of AT homozygotes patients (Table II), they were predicted radiosensitive by means of the G2 assay. Nevertheless, as they are expected to be, they were characterized as highly radiosensitive when the proposed new methodology was used. Individual radiosensitive prediction on cell lines further proved the advantages of the proposed new methodology. As can be seen in Table III, the MCF-7 cells are classified as sensitive by both methodologies while the HCC1937 cells, with a $\mathrm{G} 2$ yield of 3.1 chromatid breaks per cell, are classified as normal sensitive by the conventional method, since a cutoff value of 3.7 chromatid breaks per cell has been calculated.
However, the HCC1937 cells, which are predicted to be normal when using the conventional G2 assay, have been reported to be highly radiosensitive $(45,46)$, and this fact is confirmed when applying the proposed new methodology. Indeed, an IRP value of 2.0 chromatid breaks per cell is obtained and, therefore, as shown in Fig. 3, the cell line is classified as highly radiosensitive. In the case of GM03188 $(\mathrm{AT}+/-)$ cell line, it is characterized as radiosensitive by both methods, whereas GM15786 (AT-/-) is characterized as radiosensitive by the conventional G2 assay and as highly radiosensitive by the proposed new assay, since an IRP value of 0.9 chromatid breaks per cell was obtained. When GM09899 (control) cells were tested, they were characterized as highly radioresistant by the proposed methodology. With respect to intra-experimental reproducibility, the proposed methodology using the IRP values seems to have better reproducibility when compared to the conventional G2 assay, since lower coefficients of variation were obtained, as shown in Table III. Indeed, the fact that the IRP value is calculated for each individual as the difference between two yields of chromatid breaks obtained under exactly the same culture and irradiation conditions (culture media, $\mathrm{pH}, \mathrm{CO}_{2}$ temperature, exact radiation dose) minimizes the stringent technical requirements needed by the conventional G2 assay.

In summary, in this study it is shown that the proposed methodology for predicting intrinsic radiosensitivity and predisposition to cancer offers several advantages when compared to the conventional G2 assay, as it provides better discrimination and minimizes problems associated with intraexperimental reproducibility. The new methodology is ultimately based on differences among individuals in specific mutations or polymorphisms in genes that control: a) DNA repair capacity, b) cdk1/cyclin B activity and c) G2 checkpoint activation after irradiation during the G2 to M-phase transition. We suggest that these differences are reflected in the individual radiosensitivity parameter (IRP), which provides the biological basis of the proposed methodology, as it predicts, at individual level, the $\mathrm{G} 2$ checkpoint potential to facilitate repair of radiation-induced chromosomal damage during G2 to M-phase transition. The results obtained so far are promising and this new approach may be proved to be a simple, sensitive, reliable and clinically applicable predictive assay for the assessment of individual radiosensitivity in radiation therapy and, in general, for population screening for hypersensitivity to radiation and predisposition to cancer.

\section{References}

1. Bentzen SM: Potential clinical impact of normal-tissue intrinsic radiosensitivity testing. Radiother Oncol 43: 121-131, 1997.

2. Andreassen $\mathrm{CN}$, Alsner J and Overgaard J: Does variability in normal tissue reactions after radiotherapy have a genetic basis where and how to look for it? Radiother Oncol 64: 131-140, 2002.

3. Burnet NG, Johansen J, Turesson I, Nyman J and Peacock JH: Describing patients' normal tissue reactions: concerning the possibility of individualising radiotherapy dose prescriptions based on potential predictive assays of normal tissue radiosensitivity. Steering Committee of the BioMed2 European Union Concerted Action Programme on the Development of Predictive Tests of Normal Tissue Response to Radiation Therapy. Int J Cancer 79: 606-613, 1998. 
4. Madani I, De Ruyck K, Goeminne H, De Neve W, Thierens H and Van Meerbeeck J: Predicting risk of radiation-induced lung injury. J Thorac Oncol 2: 864-874, 2007.

5. Dikomey E, Borgmann K, Peacock J and Jung H: Why recent studies relating normal tissue response to individual radiosensitivity might have failed and how new studies should be performed. Int J Radiat Oncol Biol Phys 56: 1194-1200, 2003.

6. Borgmann K, Hoeller U, Nowack S, et al: Individual radiosensitivity measured with lymphocytes may predict the risk of acute reaction after radiotherapy. Int $\mathrm{J}$ Radiat Oncol Biol Phys 71: 256-264, 2008.

7. Alsner J, Andreassen CN and Overgaard J: Genetic markers for prediction of normal tissue toxicity after radiotherapy. Semin Radiat Oncol 18: 126-135, 2008

8. Baria K, Warren C, Eden OB, Roberts SA, West CM and Scott D: Chromosomal radiosensitivity in young cancer patients: possible evidence of genetic predisposition. Int J Radiat Biol 78: 341-346, 2002

9. Baria K, Warren C, Roberts SA, West CM and Scott D: Chromosomal radiosensitivity as a marker of predisposition to common cancers? Br J Cancer 84: 892-896, 2001.

10. Scott D: Chromosomal radiosensitivity and low penetrance predisposition to cancer. Cytogenet Genome Res 104: 365-370, 2004.

11. Ho AY, Atencio DP, Peters S, et al: Genetic predictors of adverse radiotherapy effects: the Gene-PARE project. Int $\mathrm{J}$ Radiat Oncol Biol Phys 65: 646-655, 2006.

12. Andreassen CN, Alsner J, Overgaard M, Sorensen FB and Overgaard J: Risk of radiation-induced subcutaneous fibrosis in relation to single nucleotide polymorphisms in TGFB1, SOD2 XRCC1, XRCC3, APEX and ATM - a study based on DNA from formalin-fixed paraffin-embedded tissue samples. Int J Radiat Biol 82: 577-586, 2006

13. Sanford KK, Parshad R, Gantt R, Tarone RE, Jones GM and Price FM: Factors affecting and significance of G2 chromatin radiosensitivity in predisposition to cancer. Int J Radiat Biol 55 : 963-981, 1989

14. Genetic susceptibility to cancer. ICRP publication 79. Approved by the Commission in May 1997. International Commission on Radiological Protection. Ann ICRP 28: 1-157, 1998.

15. Borgmann K, Haeberle D, Doerk T, Busjahn A, Stephan G and Dikomey E: Genetic determination of chromosomal radiosensitivities in G0- and G2-phase human lymphocytes. Radiother Oncol 83: 196-202, 2007.

16. Smart V, Curwen GB, Whitehouse CA, Edwards A and Tawn EJ Chromosomal radiosensitivity: a study of the chromosomal G(2) assay in human blood lymphocytes indicating significant interindividual variability. Mutat Res 528: 105-110, 2003.

17. Vral A, Thierens H, Baeyens A and De Ridder L: Chromosomal aberrations and in vitro radiosensitivity: intra-individual versus inter-individual variability. Toxicol Lett 149: 345-352, 2004.

18. Knight RD, Parshad R, Price FM, Tarone RE and Sanford KK: $\mathrm{X}$-ray-induced chromatid damage in relation to DNA repair and cancer incidence in family members. Int J Cancer 54: 589-593, 1993

19. Scott D, Barber JB, Spreadborough AR, Burrill W and Roberts SA: Increased chromosomal radiosensitivity in breast cancer patients: a comparison of two assays. Int J Radiat Biol 75: 1-10, 1999.

20. Scott D, Spreadborough AR, Jones LA, Roberts SA and Moore CJ: Chromosomal radiosensitivity in G2-phase lymphocytes as an indicator of cancer predisposition. Radiat Res 145: 3-16, 1996.

21. Bryant PE, Gray L, Riches AC, et al: The G2 chromosomal radiosensitivity assay. Int J Radiat Biol 78: 863-866, 2002.

22. Terzoudi GI, Jung T, Hain J, et al: Increased G2 chromosomal radiosensitivity in cancer patients: the role of cdk $1 /$ cyclin-B activity level in the mechanisms involved. Int $\mathrm{J}$ Radiat Biol 76: 607-615, 2000

23. Baeyens A, Thierens $\mathrm{H}$, Claes $\mathrm{K}$, et al: Chromosomal radiosensitivity in breast cancer patients with a known or putative genetic predisposition. Br J Cancer 87: 1379-1385, 2002.

24. Lisowska H, Lankoff A, Wieczorek A, et al: Enhanced chromosomal radiosensitivity in peripheral blood lymphocytes of larynx cancer patients. Int J Radiat Oncol Biol Phys 66: 1245-1252, 2006.

25. Parshad R, Price FM, Bohr VA, Cowans KH, Zujewski JA and Sanford KK: Deficient DNA repair capacity, a predisposing factor in breast cancer. Br J Cancer 74: 1-5, 1996.
26. Scott D, Barber JB, Levine EL, Burrill W and Roberts SA: Radiation-induced micronucleus induction in lymphocytes identifies a high frequency of radiosensitive cases among breast cancer patients: a test for predisposition? Br J Cancer 77: 614-620, 1998.

27. Howe OL, Daly PA, Seymour C, Ormiston W, Nolan C and Mothersill C: Elevated G2 chromosomal radiosensitivity in Irish breast cancer patients: a comparison with other studies. Int J Radiat Biol 81: 373-378, 2005.

28. Terzoudi GI and Pantelias GE: Conversion of DNA damage into chromosome damage in response to cell cycle regulation of chromatin condensation after irradiation. Mutagenesis 12: 271-276, 1997.

29. Pantelias GE: Radiation-induced cytogenetic damage in relation to changes in interphase chromosome conformation. Radiat Res 105: 341-350, 1986.

30. Cheng X, Pantelias GE, Okayasu R, Cheong N and Iliakis G: Mitosis-promoting factor activity of inducer mitotic cells may affect radiation yield of interphase chromosome breaks in the premature chromosome condensation assay. Cancer Res 53: 5592-5596, 1993.

31. Terzoudi GI and Pantelias GE: Cytogenetic methods for biodosimetry and risk individualisation after exposure to ionising radiation. Radiat Prot Dosimetry 122: 513-520, 2006.

32. Terzoudi GI, Manola KN, Pantelias GE and Iliakis G: Checkpoint abrogation in G2 compromises repair of chromosomal breaks in ataxia telangiectasia cells. Cancer Res 65: 11292-11296, 2005.

33. Scott D, Hu Q and Roberts SA: Dose-rate sparing for micronucleus induction in lymphocytes of controls and ataxiatelangiectasia heterozygotes exposed to 60Co gamma-irradiation in vitro. Int J Radiat Biol 70: 521-527, 1996.

34. Parshad R, Sanford KK and Jones GM: Chromatid damage induced by fluorescent light during G2 phase in normal and Gardner syndrome fibroblasts. Interpretation in terms of deficient DNA repair. Mutat Res 151: 57-63, 1985.

35. Parshad R, Gantt R, Sanford KK and Jones GM: Chromosomal radiosensitivity of human tumor cells during the $\mathrm{G} 2$ cell cycle period. Cancer Res 44: 5577-5582, 1984.

36. Sanford KK, Parshad R, Price FM, et al: Enhanced chromatid damage in blood lymphocytes after G2 phase x irradiation, a marker of the ataxia-telangiectasia gene. J Natl Cancer Inst 82: 1050-1054, 1990

37. Papworth R, Slevin N, Roberts SA and Scott D: Sensitivity to radiation-induced chromosome damage may be a marker of genetic predisposition in young head and neck cancer patients. Br J Cancer 84: 776-782, 2001.

38. Scott D, Spreadborough A, Levine E and Roberts SA: Genetic predisposition in breast cancer. Lancet 344: 1444, 1994.

39. Terzoudi GI, Singh SK, Pantelias GE and Iliakis G: Premature chromosome condensation reveals DNA-PK independent pathways of chromosome break repair. Int J Oncol 33: 871-879, 2008.

40. Iliakis G, Wang H, Perrault AR, et al: Mechanisms of DNA double strand break repair and chromosome aberration formation. Cytogenet Genome Res 104: 14-20, 2004.

41. Koch K, Wrona A, Dikomey E and Borgmann K: Impact of homologous recombination on individual cellular radiosensitivity. Radiother Oncol 90: 265-272, 2009.

42. Natarajan AT and Palitti F: DNA repair and chromosomal alterations. Mutat Res 657: 3-7, 2008

43. Wu W, Wang M, Mussfeldt T and Iliakis G: Enhanced use of backup pathways of NHEJ in G2 in Chinese hamster mutant cells with defects in the classical pathway of NHEJ. Radiat Res 170: 512-520, 2008.

44. Pawlik TM and Keyomarsi K: Role of cell cycle in mediating sensitivity to radiotherapy. Int J Radiat Oncol Biol Phys 59: 928-942, 2004.

45. Foray N, Arlett CF and Malaise EP: Underestimation of the small residual damage when measuring DNA double-strand breaks (DSB): is the repair of radiation-induced DSB complete? Int J Radiat Biol 75: 1589-1595, 1999.

46. Chen MF, Lin CT, Chen WC, et al: The sensitivity of human mesenchymal stem cells to ionizing radiation. Int $\mathrm{J}$ Radiat Oncol Biol Phys 66: 244-253, 2006.

47. Natarajan AT, Obe G and Dulout FN: The effect of caffeine post treatment on X-ray induced chromosomal aberrations in human blood lymphocytes in vitro. Hum Genet 54: 183-189, 1980.

48. Natarajan AT, Meijers M, van Zeeland AA and Simons JW: Attempts to detect ataxia-telangiectasia (AT) heterozygotes by cytogenetical techniques. Cytogenet Cell Genet 33: 145-151, 1982. 